\title{
Educação Musical, relações étnico-raciais e decoloneidade: tensões, perspectivas e interações para a Educação Básica
}

Leonardo Moraes Batista*

Universidade Federal do Rio de Janeiro leonardomoraesbatista@gmail.com

*Presidente do Fórum Latinoamericano de Educação Musical - FLADEM (2017-2017). Licenciado em Música e Especialista em Educação Musical pelo Conservatório Brasileiro de Música (UNICBM). É Mestre em Música e Doutorando em Etnomusicologia pela Universidade Federal do Rio de Janeiro (UFRJ).

Submetido em 30/04/2018, Aprovado em 29/10/2018 


\section{Resumo}

O presente ensaio problematiza a educação das relações étnico-raciais para além de um "conteúdo" dos componentes curriculares, mas principalmente como uma Esse artigo aponta tensões e aborda perspectivas e interações sobre a decoloneidade para o campo da Educação Musical, com foco na Educação Básica, perpassado pelo debate acerca da Educação das Relações Étnico-Raciais para o ensino da História e Cultura Afro-Brasileira e Africana. $O$ texto aponta silenciamentos e invisibilidades causadas pelos epistemicídios presentes nos currículos e práticas pedagógico-musicais causado por um negrocídio, e apresenta perspectivas epistemológicas e interações curriculares para uma ação pedagógico-musical outra. É empregado, no decorrer do artigo, o enfoque da pesquisa subjetivista, abrangendo o campo teórico com base em perspectivas político-epistemológicas e legislativas, em diálogo com as vozes de autoras e autores que convido para discutir o tema. Proponho um caminho desobediente às hegemônicas ações estabelecidas pelas estruturas do patriarcalismo, do capitalismo e do colonialismo, impregnados e institucionalizados na sociedade que subalterniza, silencia e invisibiliza a ideia de projeto educativo emancipatório, visto de um âmbito pedagógico-musical.

Palavras-chave: educação musical, relações étnico raciais, decoloneidade, currículo, educação básica.

\section{Abstract}

This article points out tensions and approaches perspectives and interactions for decolonization in the field of Music Education, focusing on Basic Education, passing through the debate about Ethnic-Racial Relations Education for the teaching of Afro-Brazilian and African History and Culture. The text points to silences and invisibilities caused by the epistemicides present in curricula and pedagogical-musical practices, given by a Negrocide and presents epistemological perspectives and curricular interactions, for a pedagogical-musical action another. The article focuses on subjectivist research, covering the theoretical field based on political-epistemological and legislative perspectives, in dialogue with the voices of authors and authors that I invite to discuss the theme. I propose a path disobedient to the hegemonic actions established by the structures of patriarchalism, capitalism and colonialism, impregnated and institutionalized, in society that subalternizes, silences and invisibilizes the idea of emancipatory educational project, seen from a pedagogical-musical scope.

Keywords: musical education, racial ethnic relations, decoloneity, curriculum, basic education. 
Uma epistemologia do Sul assenta em três orientações: aprender que existe o Sul;

aprender a ir para o Sul;

Aprender a partir do Sul e com o Sul.

(Boaventura Sousa Santos, 1995)

\section{O ponto de partida é o Sul em diálogo com o Sul}

Ao evocar Boaventura nessa epígrafe destaco três pontos para iniciarmos nossa conversa. O primeiro deles trata da demanda emergente de realizarmos uma virada epistemológica nos processos de ensinoaprendizagem ${ }^{1}$ da Educação Musical nas escolas de Educação Básica. É necessário e imperativo aprendermos que existem outras formas de enxergar o Mundo e, nesse aspecto em especial, aprender com o Sul, sobre o Sul: um caminho possível a se percorer.

O segundo ponto se refere à urgente necessidade de rompimento com a estrutura monocultural, colonizadora e epistemicida que norteia currículos e propostas do fazer musical, ainda estruturada sobre os modelos eurocêntricos e prescritos, distantes do que é praticado no cotidiano das escolas. Ou seja, é indispensável a construção de políticas e estratégias pedagógico-musicais comprometidas com a diversidade cultural que existe nos espaços de Educação.

A terceira questão está calcada na necessidade de pensarmos uma formação humana, por meio da e com a Música, na sua pluralidade interétnica e de forma decolonial, em que os modelos hegemônicos não sejam mais mantidos em primeiro plano como uma ordem superior aos outros conhecimentos, mas continuamente confrontados, debatidos e deslocados da supremacia que desgiletima saberes outros existentes no Mundo.

Chamo a atenção a esses três pontos por perceber que, na contemporaneidade, o processo de Educação Musical escolar não comporta mais a obediência a uma ordem epistemicida, que desconsidera identidades culturais, jogando no abismo toda uma multiplicidade musical desenvolvida por uma pluralidade humana.

É nesse bojo de muitas expressões, culturais e musicais, que o currículo pode e mesmo necessita ser construído, não mais colonizado sobre uma perspectiva desigual e racista, mas aberto ao diálogo contínuo e sistemático com outras produções musicais que não foram e ainda não têm permissão de fazer parte do escopo curricular do ensinoaprendizagem de Música na Educação Básica.

Nessa margem de problematização sobre a Música na escola, com diálogo entre currículo, relações étnico-raciais e decoloneidade, apontarei as tensões existentes no que se pratica, em termos de processo de Educação Musical, para debater as questões hegemônicas, excludentes e perversas que o colonialismo e a colonialidade abis-

\footnotetext{
$1 \quad$ Utilizo ensinoaprendizagem conectado por entender que este processo é continuamente interligado no dia a dia da sala de aula. Essa, e as demais que aparecerão no decorrer do texto, tem o sentido de discutir as dicotomias que, a meu ver, dentro de uma ideia de processo educativo emancipatório, não seguem separadas e, sim, conectadas e em contínuo diálogo pela aplicabilidade que elas possuem. Vale destacar que é comum aos pesquisadores/as e afiliados/as à linha de pesquisa nos/dos/com os cotidianos escolares (ALVES; OLIVEIRA, 2008) criarem neologismos quando não encontram uma única palavra que dê conta do que se pretende dizer.
} 
salmente demarcam às práticas pedagógico-musicais. No que se refere às interações, também chamo a atenção para pensarmos em uma relação decolonial crítica para o campo da Educação Musical, sob a perspectiva de reinventarmos os nossos currículos e as nossas práticas pedagógicas diante dos debates que a contemporaneidade nos aponta. Esse texto não possui o intuito de apontar respostas. Porém, ao levantar questões, provocarmo-nos a repensar desobedientemente os paradigmas que sustentam a base de ensinoaprendizagem musical vigente: branca, colonialista e racista.

Assim, proponho algumas questões que poderão auxiliar na produção dessa conversa. Até que ponto a perspectiva colonial eurocentrada, demarcada no processo de Educação Musical na Educação Básica, inferioriza, subalterniza e desgiletima conhecimentos outros? Por quais caminhos e possibilidades podemos transitar para trazer ao currículo da Educação Básica diversificadas fundamentações teóricas e epistemológicas, não eurocêntricas, para a prática da formação humana nas ações educativas dos/nos cotidianos das escolas? Como a ideia de pedagogia decolonial pode contribuir para inserções de práticas pedagógico-musicais comprometidas com a erradicação do racismo por meio de um currículo de ensinoaprendizagem musical que abarque a diversidade musical e a pluralidade étnica do Mundo? Levando em conta as orientações das Diretrizes Curriculares Nacionais para Educação das Relações Étnico-Raciais e para o ensino da História e Cultura Afro-Brasileira e Africana (2004) em contraponto com as Diretrizes Nacionais para a operacionalização do ensino de Música na Educação Básica (2016), como nós, educadores musicais, podemos contribuir para a erradicação do racismo por meio de práticas contra-hegemônicas e pedagogias mais abertas?

Essas perguntas e provocações serão debatidas no decorrer do texto com o intuito de pensarmos na ideia de descolonização centrada no combate ao racismo, longe da ideia de branquitude, no processo de Educação Musical na/para Educação Básica brasileira, com foco nas perspectivas e interações que cercam a discussão. Para que o texto não pareça vitimatório, messiânico e panfletário², irei dialogar com alguns autores que hoje são muito caros para o debate da descolonização do poder, do saber e do ser. São eles: Nilma Lino Gomes (2012; 2017), Djamila Ribeiro (2017), Walter Mignolo (2017) e Boaventura Souza Santos (2010). A escolha desses autores se deu pelo enfrentamento aos fatos negrocídas dados na contemporaneidade e a oportunidade de vislumbrar uma discussão do Sul com o Sul.

Também trarei para o texto as problematizações das políticas públicas das ações afirmativas travadas fortemente pelo Movimento Negro, com foco no campo da Educa-

\footnotetext{
2 "Vitimatório, messiânico e panfletário" foram as palavras usadas pelo parecer da Comissão Científica do XXIII Congresso Nacional da Associação Brasileira de Educação Musical - ABEM, em 2017, sobre o Simpósio intitulado "Educação Musical, Cultura e Relações Étnico-Raciais: reflexões político-epistemológicas-pedagógicas". Esse texto foi produzido por negros/a pesquisadores/a, docentes e ativistas, que possuem seu lugar de fala e no seu campo de atuação - Educação Musical. O texto trata da questão do racismo por meio da invisibilidade negra nos processos pedagógico-musicais. Os quatro artigos que compunham o simpósio foram rechaçados, por motivos que não alcançam o cerne das problematizações por destacar questões de ordem legislativas e sociológicas. 0 texto foi submetido ao GT 1.2 - Epistemologia da Educação Musical. Vemos este parecer como um ato de violência, desencadeado pelo despreparo profissional e racista de um determinado grupo de pareceristas convidados para tal ação, pela falta de entendimento sobre os saberes e conhecimentos do povo negro e uma condenação que advém do cientificismo branco, patriarcal e colonialista, o que tem causado, na produção de conhecimento, a impossibilidade de existência da negritude. É isso, o racismo patriarcal, branco e colonialista achou que não teríamos nada a dizer. Expomos as atrocidades com consistência e coerência e nesse caminho ressurgiremos, reemergiremos e (re)existiremos contra o racismo epistêmico.
} 
ção, são elas as Diretrizes Curriculares Nacionais para a Educação das Relações Étnico-Raciais e para o ensino da História e Cultura Afro-Brasileira (2004) e a Lei 10.639/2003

\section{Lei 10.639/2003: um marcador emergente para a Educação Musical}

No intuito de ampliar o debate aqui desenvolvido destaco um marcador e alguns aspectos políticos e epistemológicos que nos auxiliarão. A escolha pelo foco e destaque da Lei 10.639/2003 vem ao encontro do que está centrado na ação política de ações afirmativas lideradas pelo Movimento Negro, demarcado por luta, resistência e resiliência, e tem como objetivo a reparação histórica, o reconhecimento e a valorização da história e a construção de oportunidades iguais, em parâmetros econômicos, sociais, educacionais e culturais, para negros e negras brasileiros.

Embasado por referenciais teóricos que mergulham nas ideias do subtítulo, componho um trajeto com o olhar sobre o ensinoaprendizagem de Música na Educação Básica. Vale ressaltar, antes de tudo, que o cotidiano a qual legitimo destaque é atravessado por crenças, valores, dores, angústias e desejos de indivíduos plurais, que circulam nesse espaço - escola, composto por tensões, conflitos e produções de sentidos e significados.

Porém, os sentidos e os significados que são emaranhados nas redes de saberes e conhecimentos ampliados na escola - em diálogo com o que acontece no cotidiano das crianças, dos adolescentes, jovens, adultos e idosos, praticantes (CERTEAU, 1994) da Educação Infantil, do Ensino Fundamental (dos anos iniciais e finais), Ensino Médio e Educação de Jovens e Adultos - perpassam, alguns desses indivíduos, por uma espécie de ação que envolve apagamento, silenciamento, subalternização e indiferença.

Ao organizarmos, por exemplo, o planejamento da prática pedagógica musical para um desses segmentos destacados acima, para o decorrer do ano vigente na escola, passa pela nossa consciência e, logo pela nossa responsabilidade social como docente, que o Brasil é o país com o mais alto índice de assassinatos de negros e negras?

A campanha intitulada "Jovem Negro Vivo", promovida pela Anistia Internacional do Brasil ${ }^{3}$, lançada em novembro de 2014, denuncia o alto índice de homicídios de jovens negros em nosso país. É apontado, por meio de confirmação estatística, que o Brasil é o país onde mais se mata no mundo: para se ter uma ideia, entre 2004 e 2007, cerca de 170 mil pessoas foram mortas nos doze maiores conflitos mundiais, como Paquistão, Israel e Palestina. Nesse comboio da chacina simbólica e física da "carne negra", nesse mesmo período, o Brasil ultrapassou o quantitativo de mais de 190 mil mortes, tendo como principais vítimas os jovens com faixa etária variante entre 15 e 29 anos. Desse registro de mortes, no Brasil, anualmente morrem 30 mil jovens vítimas de homicídio, 0

A Anistia Internacional, fundada em 1961, é um movimento/rede que realiza ações e campanhas para que os Direitos Humanos internacionalmente reconhecidos sejam respeitados e protegidos. Esta rede está presente em mais de 150 países e tem seu foco de ação centrado nos Direitos Humanos por meio do debate que envolve justiça, igualdade e liberdade. Teve sua sede inaugurada no Brasil em 2012 e é independente de qualquer governo, ideologia política, interesse econômico ou religião. A campanha "Jovem Negro Vivo" teve ampla repercussão na cidade do Rio de Janeiro e em outros estados. Para maiores informações ver: <https://anistia.org.br/campanhas/jovemnegrovivo/>. Os dados coletados para o desenvolvimento da pesquisa e para a produção da campanha tiveram como base o Mapa da Violência 2014: os jovens do Brasil. Para maiores informações ver: <http://www.mapadaviolencia.org.br/mapa2014_atualiza15a29.php >. 
que corresponde a 82 jovens por dia. Desse quantitativo, 77\% são negros. Ou seja, $21 \mathrm{mil}$ jovens negros que experimentam a desigualdade social por meio do racismo estrutural na/da base da sociedade brasileira e o genocídio institucionalizado pelo Estado, que há anos, no Brasil desumaniza, inferioriza, reduz, destroça, apaga, invisibiliza, mata, violenta, marginaliza e exclui a população negra de formas diversificadas.

Sinalizo que esses dados podem também ser encontrados e comprovados no Atlas da Violência de $2017^{4}$, trabalho de pesquisa estatística desenvolvido pelo Instituto de Pesquisa Econômica Aplicada - IPEA - em parceria com o Fórum Brasileiro de Segurança Pública. O Atlas deixa explícito que jovens e negros são as principais vítimas de violência no país. Os dados assustadores apontam a incapacidade do Estado de combater o racismo que é alimentado pela legitimação da desigualdade, discriminação e inferioridade da população negra.

Segundo os dados do Atlas da Violência, de cada 100 pessoas que sofrem homicídio no Brasil, 71 são negras. É apontado que o "cidadão negro possui chances $23,5 \%$ maiores de sofrer assassinato em relação a cidadãos de outras raças/cores, já descontado o efeito da idade, sexo, escolaridade, estado civil e bairro de residência". Um marcador da violência escancarada é que "os negros com idade entre 12 e 29 anos apresentavam mais risco de exposição à violência que os brancos na mesma faixa etária, ou seja, o risco relativo de um jovem negro ser vítima de homicídio era 2,6 x maior do que um jovem branco" (IPEA, 2017, p. 30-31).

Entre os anos de 2005 e 2015 houve um crescimento de 18,2\% na taxa de homicídio de negros. A taxa de brancos diminuiu 12,2\%. O estudo realizado destaca que "apesar do avanço em indicadores socioeconômicos e da melhoria das condições de vida da população entre 2005 e 2015, continuamos uma nação extremamente desigual, que não consegue garantir a vida para parcelas significativas da população, em especial à população negra" (IPEA, 2017, p. 31). Um ponto de atenção: 54\% da população brasileira é negra e sofre com o genocídio cotidianamente.

Os dados nos chamam a atenção. Creio que não é mais possível em nosso processo de Educação Musical escolar não refutarmos o nosso currículo que ainda é racista e epistemicida. É necessário que nós educadores tenhamos o compromisso ético e a responsabilidade social com estes indivíduos que são cotidianamente lembrados que a negritude ocupa um lugar de inferioridade.

A condição social do negro no Brasil deve ser levada em consideração para esta análise, não só em termos numéricos ou estatísticos da atualidade, mas cabe observar a historicidade e importância do/a negro/a como ator social relevante na sociedade brasileira, especialmente a crítica a um modelo social construído a partir de hierarquias que também têm características raciais e poderão contribuir para a elucidação e compreensão das demandas sociais em geral, e raciais em especial.

O texto de Abdias Nascimento, intitulado O Genocídio do Negro Brasileiro: processos de um racismo mascarado, proclamado durante Colóquio do Festival Mundial de Artes e Culturas Negras e Africanas, em 1977, denuncia a falácia e o mito da democracia

4 Para maiores informações e mergulhos nos perversos dados da estatística brasileira, ver: <http://www.ipea.gov.br/atlasviolencia/>. 
racial $^{5}$, imposta aos afrodescendentes brasileiros e seus efeitos políticos, econômicos, sociais, culturais e educacionais que até hoje, na contemporaneidade, são percebidos enquanto estrutura institucionalizada de violência do homem negro e da mulher negra no Brasil. O conceito de democracia racial erigiu-se no Brasil a partir de especulações, com o apoio das chamadas ciências históricas e com determinada relação concreta na dinâmica da sociedade brasileira: que negros e brancos têm uma convivência harmônica, e que desfrutam de oportunidades iguais de existência, sem interferência de origens raciais ou étnicas.

O entendimento e localização postos pela grosseira estrutura da branquitude ao colocar os negros como inferiores, por diversos fatores da historicidade brasileira, revelam a perversa e violenta ideia designada democracia racial, que só concede aos negros um único "privilégio": o de se tornarem brancos, por dentro e por fora, bem com Frantz Fanon ${ }^{6}$ (2008) já apontava em Peles negras, máscaras brancas. Ou seja, um aspecto de embranquecimento cultural. O racismo epistêmico é uma das dimensões mais perniciosas da discriminação étnico-racial. Em linhas gerais, significa a recusa em reconhecer que as produções de conhecimento de algumas pessoas sejam válidas por duas razões: a primeira por não serem brancas e a segunda porque produções de conhecimento envolvem repertório e cânones que não são ocidentais.

Em processos pedagógico-musicais, essa visão discriminatória é amplamente visível, tanto no aspecto epistemológico de base de ensinoaprendizagem, quanto nas metodologias que se utilizam para esse processo. Aponto crítica a essa questão porque cunhamos no paradigma estético, pedagógico e cultural uma ação pitagórica que nos impede de pensar em outros modos e estruturas de fazer música nos espaços educativos. São utilizadas métodos ativos, teoria, harmonia, história da música, sob a concepção eurocêntrica, por exemplo, para ensinar música desde a escola de Educação Básica até a Universidade no Brasil, que possui um vasto arcabouço de saberes outros e um riquíssimo campo epistemológico multicultural e étnico, em âmbito estético e simbólico. Ou seja, o epistemicídio contínuo nos espaços educativos é gritante. Pode-se dizer que vai da formação de professores até o cotidiano da sala de aula. fundamental que estejamos engajados para a construção de pedagogias que desfaçam equívocos construídos sobre a base do mito de democracia racial, utilizando da diversidade sonora-musical que esse país possui, com mola impulsora para uma outra forma de aprendizagem e por seguinte o combate ao racismo.

Diante dos aspectos ressaltados, se comprova que o Brasil é um país racista. Não sou eu quem digo, é a ONU7. Parto do princípio de que é possível a inserção no currículo

\footnotetext{
5 Autores com Lélia Gonzáles, Abdidas Nascimento, Jurema Werneck, Sueli Carneiro, Nilma Lino Gomes, Kabenguele Munanga, Beatriz Petronilha da Silva, Carolos More, tem apontado o falso mito da democracia racial no Brasil.

6 Pele negra, máscaras brancas é um livro que foi escrito em 1952 e que virou referência para os movimentos anticolonialistas africanos e caribenhos, e também - porque não? - para a incipiente articulação dos movimentos pela dignidade negra nas Américas, como o movimento negro brasileiro capitaneado por Abdias do Nascimento, e, nos EUA, pelos movimentos civis como o Black Panthers e Black Power, dentre outros da década de 1960. Natural da Martinica, ilha caribenha sob jugo Francês, Frantz Fanon nasceu em 1925, formou-se em Medicina na cidade de Lyon, onde se especializou em psiquiatria e estudou também filosofia e literatura.
}

7 A ONU Brasil lançou no dia 7/11/2017, a campanha \#VidasNegras, iniciativa de conscientização nacional pelo fim da violência contra 
de educação musical o debate político-epistemológico, que ressalte as práticas pedagógicas, musicais e culturais afrodescendentes, que, por muito tempo, foram silenciadas, menosprezadas e inferiorizadas, na escola, espaço de formação humana.

Assim, parte-se da ideia em conjunto com Ângela Davis ${ }^{8}$ (2017) sobre a atenção, que o empoderamento é ação que se constrói junto, ou seja, a questão do racismo não é apenas para os/as negros/as resolverem: é algo de todo indivíduo humano.

É necessário que nós, docentes e pesquisadores, possamos romper com a única história contada até agora, esta hegemônica e suprema no Mundo, como nos lembra Chimamanda Ngozi Adichie ${ }^{9}$ (2009), sobre a ameaça que paira sobre nós ao concordarmos e legitimarmos em nossos fazeres uma única fonte, a eurocêntrica. Temos orientações curriculares dadas pelo Ministério da Educação, bem como direcionamentos que o próprio cotidiano nos apresenta, a partir da pluralidade humana que existe no Mundo.

No que se refere ao grande avanço que tivemos com a implementação da Lei 11.769/2008 que altera a Lei de Diretrizes e Bases de Educação Nacional (LDBEN) 9.394/1996 para tornar o ensino de Música obrigatório na Educação Básica, indago: que tipo de Música é ensinado na escola? Obedecem aos padrões eurocêntricos que massacraram a África e milhares de Indígenas pelas Américas? Há uma imposição de um repertório e de uma forma de pensar esse ensino por um único viés, condenando as demais formas de praticar Música na sala de aula? Excluí-se desse universo impositivamente musicalidades e epistemologias da negritude?

Levanto essas questões por perceber que a Lei 10.639/2003 aponta para o estabelecimento, na LDBEN, da inclusão no currículo da Educação Básica a obrigatoriedade do estudo da História da África e dos Africanos, a luta dos negros no Brasil, a cultura negra brasileira e o negro na formação da sociedade nacional, resgatando a contribuição do povo negro nas áreas social, econômica e política, pertinentes à História do Brasil.

\footnotetext{
a juventude afrodescendente. Em cerimônia que reuniu em Brasília cerca de cem autoridades públicas e representantes da sociedade civil e do corpo diplomático, dirigentes das Nações Unidas alertaram que cinco jovens negros morrem a cada duas horas no país. Por ano, o número chega a 23 mil. Para Nicky Fabiancic, coordenador-residente do Sistema das Nações Unidas no Brasil, os dados mostram a "dura realidade" enfrentada pela juventude negra brasileira, "que sofre o impacto do racismo estrutural que precisamos combater". "Hoje, reafirmo o compromisso da equipe das Nações Unidas no Brasil com a eliminação do racismo e da discriminação racial. A campanha Vidas Negras é uma convocatória à ação. É inaceitável que o fato de ser negro coloque jovens em risco de serem assassinados, de serem submetidos a diferentes tipos de violência. As famílias temem pelas vidas desses jovens. Perdem esses jovens. E a sociedade: nós perdemos muito mais", afirmou o dirigente durante o evento na Casa da ONU, na capital federal. "Precisamos reconhecer que afrodescendentes são as maiores vítimas de ações abusivas e, muitas vezes, letais pelas forças de segurança, ocasionando também taxa desproporcional de aprisionamento de pessoas negras. 0 coordenador-residente enfatizou a responsabilidade que o poder público tem de reverter o atual cenário, sobretudo devido às dificuldades que a juventude negra enfrenta para ter acesso à educação. Cobrando medidas para "manter o jovem negro na escola", Fabiancic completou que "isso deve ser combatido nas frentes social, política e econômica para que se reverta essa profunda desigualdade". Ver: <https://nacoesunidas.org/o-racismo-mata-e-nao-podemos-ser-indiferentes-diz-onu-brasil-em-lancamento-da-campanha-vidasnegras/>.
}

8 Agela Yovonne Davis, nasceu em Birminghan - EUA, em 26 de janeiro de 1944. É professora, filosofa e feminista. Alcançou notoriedade mundial na década de 1970, como integrante do Partido Comunista dos Estados Unidos, dos Panteras Negras, por sua militância e ativismo pelos direitos das mulheres negras e contra a discriminação racional nos EUA. Para maiores informações ver: <https://www.geledes.org.br/angela-davis/>.

9 Chimamanda Ngozi Adichie mulher nigeriana e escritora e é uma das mais reconhecidas no meio das escritoras jovens anglófonas. Autora de publicações importantes ao debate do feminismo e feminicídio tais como: No seu pescoço (2009), Sejamos todos Feministas (2014), Hibisco Roxo (2016), Para Educar Crianças Feministas (2017), são potentes exemplos da pensadora que esteve no evento intitulado Tecnology, Entertainment and Design - TED, em 2009 e provoca os/as participantes sobre a reflexão do perigo de uma única história, pode ser um problema para a sociedade do/no Mundo. Para ampliação da fala da autora ver: <http://www.bocc.ubi.pt/pag/alves-alves-o-perigo-da-historia-unica.pdf ou https://www.youtube.com/watch?v=wQk17RPuhW8>. 
Logo após a promulgação da Lei, foram aprovadas em 10/3/2004 as Diretrizes Curriculares Nacionais para Educação das Relações Étnico-Raciais e para o Ensino de História e Cultura Afro-Brasileira e Africana, com o objetivo de "promover alteração positiva na realidade vivenciada pela população negra e trilhar rumo a uma sociedade democrática, justa e igualitária, revertendo os perversos efeitos de séculos de preconceito, discriminação e racismo" (BRASIL, 2004, p. 8). Esse documento orienta docentes quanto aos processos pedagógicos e também a (re)pensar um currículo amplo com dimensões abertas para um processo de erradicação do racismo por meio do reconhecimento de África e dos Afro-Brasileiros por um outro viés. Não a par do que conseguiram insurgir em nossas subjetividades no decorrer dos anos, por exemplo: aquela África miserável, pobre, subalterna e devastada. Mas, sim, uma África com ampla diversidade cultural de línguas, musicalidades e humanidades.

Nessa direção, temos no Brasil, na nossa musicalidade, a presença demarcada de aspectos que legitimam a herança africana. Vemos essa contribuição pontuada em muitas sonoridades do construto musical brasileiro, e hoje também sob a luz e interesse das pesquisas desenvolvidas em Programas de Pós-Graduação em Música, especialmente os da linha de Etnomusicologia e Educação Musical. Um exemplo para destaque sobre a questão apontada é o trabalho intitulado "Culturas Musicais Afro-Brasileiras: perspectivas para concepções e práticas etnoeducativas em Música"10, publicado no livro Etnomusicologia no Brasil (2017), em que os/as autores/as do texto apontam:

Em um novo contexto paradigmático, a etnomusicologia no Brasil passou a trabalhar em prol da promoção de novas interseções epistemológicas e interações na produção de conhecimentos, sobretudo a partir das abordagens etnográficas das práticas musicais tradicionais, sejam elas urbanas, rurais ou midiáticas, de afrodescendentes, em suas dimensões rituais, estéticas, sociais e culturais (LUCAS et al., 2017, p. 258).

Ressaltar que essa produção existe e que tais práticas pedagógicas musicais a partir de um viés epistemológico da negritude no Brasil é um caminho, e/ou uma possibilidade, de (re)pensarmos paradigmas estéticos outros para inserção no currículo de ensinoaprendizagem de Música na escola. É nosso compromisso ético com saberes, conhecimentos e vidas subalternizadas e escravizadas pela perversidade do mundo obscuro que se emprega na falsa ideia de democracia racial, que joga no abismo os conhecimentos plurais que advêm de África e são invisibilizados nos currículos de Educação Básica.

\footnotetext{
10 Texto composto por Glaura Lucas, Luis Ricardo Silva Queiroz, Luciana Prass, Fábio Henrique Ribeiro, Rubens de Oliveira Aredes. Faz parte da publicação intitulada Etnomusicologia no Brasil, com Organização de Angela Luhning e Rosângela Pereira de Tugny. 0 texto apresenta "consolidação de algumas políticas públicas voltadas a ações afirmativas para a população afrodescendente, ao mesmo tempo em que o ensino de música institucionalizado no Brasil vem passando por transformações significativas. Diante dessa conjuntura, a publicação discute e analisa perspectivas e desafios para a aplicação conjunta de duas leis relativas a esse processo, a saber: a lei n. ${ }^{0}$ 10.639/2003, que define 'História e cultura afro-brasileiras' como temáticas obrigatórias na educação básica, e a lei n. ${ }^{\circ} 11.769 / 2008$, que trata da música como conteúdo curricular obrigatório. Destacam-se aqui os aspectos relacionados à inserção e abordagem de saberes musicais de culturas afro-brasileiras no universo da formação escolar, tendo como base o diálogo e a interseção entre etnomusicologia e educação musical. As reflexões realizadas no texto denotam que conhecimentos produzidos nesses dois campos têm potencial para nortear concepções e práticas de ensino de música nas escolas com vistas a contemplarem adequadamente as especificidades dos saberes musicais afro-brasileiros" (LUCAS et al., 2017, p. 299).
} 
É necessário destacar e ampliar a lente sobre o diálogo entre o campo da Educação Musical e o da Etnomusicologia brasileiras, que, a partir de seu compromisso social e posicionamento político, tem levantado o debate de se pensar a Música de uma maneira diferente, ou seja, para além do cânone da "música erudita", contemplando o paradigma da diversidade cultural. Acredita-se no potencial de prática de uma musicalidade outra, abrindo espaço para a reinvenção da Música.

A etnomusicologia brasileira vem realizando pesquisas expressivas nas duas últimas décadas no campo da etnomusicologia. As práticas e pesquisas desenvolvidas no campo têm se utilizado de inovações teóricas, metodológicas e epistemológicas, nas quais se amplia o entendimento de Música e de quem a faz. As práticas musicais têm sido tomadas como dispositivos políticos de resistência e resiliência, em diversificados processos sociais da contemporaneidade. A produção na área e o diálogo com o campo da educação musical tem ampliado a possibilidade de se trabalhar com a diversidade cultural brasileira ${ }^{11}$. Lucas et al. (2017) sinalizam que

A aproximação teórica entre saberes da educação musical e da etnomusicologia não é recente e vem sendo promovida e discutida, no Brasil, a partir de motivações e perspectivas varridas (ARROYO, 1999, 2002, 2003; LUCAS, 1995; LUCAS et al., 2003; PRASS, 2005, QUEIROZ, 2010; STEIN, 1998). Pesquisas etnomusicológicas sobre culturas musicais diversas, ao longo do século $\mathrm{XX}$, em geral, situações e estratégias de formação em música, abrangendo processos de enculturação que dão no cotidiano da vida social; caminhos estabelecidos para o ensino formal especializado; modos com tradições musicais são transmitidas e perpetuadas através de gerações, entre dimensões da complexa teia que caracteriza a formação musical humana. (LUCAS et al., 2017, p. 249)

Destaco como exemplo a ação formativa do Projeto Encontro de Saberes ${ }^{12}$ que possui foco no encontro de saberes plurais, com perspectivas de ensinoaprendizagem diversificadas, e que reconhecem a Música com fenômeno. O projeto é uma iniciativa do Instituto Nacional de Ciência e Tecnologia de Inclusão Superior e na Pesquisa (INCTI), implantado na Universidade de Brasília (UnB) e em outras universidades do país, tais como: Universidade Federal de Minas Gerais (UFMG), Universidade Federal de Juiz de Fora (UFJF), Universidade Federal do Cariri (UFCA), Universidade Federal do Ceará (UFC) e Universidade Federal do Pará (UFPA). A ação do Encontro de Saberes persiste no processo político-epistemológico que permite aos mestres dos saberes tracionais atuarem como professores nas universidades, como uma experiência transdisciplinar e multicultural.

O projeto tem o objetivo de introduzir os saberes e conhecimentos tradicionais, historicamente excluídos e subalternizados nos espaços de ensino superior, como forma de ampliação epistêmica nos currículos das universidades brasileiras, que, de alguma forma, ainda estão embasados pela perspectiva moderna ocidental. Com o título 0

\footnotetext{
11 Para maiores informações acerca do debate e do diálogo entre as áreas de Educação Musical e Etnomusicologia ver: Campbell (2003, 2017) Lühing (2014), Tugny (2014) e Marinho e Queiroz (2017).

12 Ver Carvalho (2010, 2011) e Carvalho e Águas (2015).
} 
encontro de saberes com uma contribuição à Etnomusicologia e à Educação Musical, publicado no livro Etnomusicologia no Brasil, é possível perceber a dimensionalidade da ação do projeto, ao possibilitar, em tempo de formação docente, por um exemplo, encontro com saberes necessários as demandas da contemporaneidade e aos aspectos debatidos nesse artigo.

Desenvolver abordagens pedagógico-musicais com foco na proliferação de saberes pode ser um caminho essencial para se pensar o cotidiano das escolas de Educação Básica, visto que é necessário tomar conhecimento da complexidade que envolve a construção da identidade negra no Brasil, um país multiétnico e pluricultural. Ou seja, o movimento interétnico, no processo de Educação Musical pode ser uma ferramenta de erradicação do racismo e visibilidade na produção de conhecimento daqueles e daquelas que, cotidianamente, praticam saberes na sala de aula. Saberes esses que fazem parte da história ancestral, não mais subalternizada, mas vivida no seio da emancipação do branqueamento, sob a diversidade étnica.

Desse modo, como é possível realizar um projeto educativo emancipatório de Educação Musical para além dos conflitos e tensões demarcados pela herança racial do colonialismo no Brasil? Sinalizo que não possuo respostas específicas ou direcionamentos, mas apresento a observação de que, sendo o país uma sociedade multicultural e pluriétnica, não é mais possível pensarmos o padrão de práticas pedagógicas musicais com a única história demarcada e legitimada nos processos de formação docente inicial e continuada. É fundamental pensarmos a pluralidade de saberes e conhecimentos que nos circundam, expressam e difundem sonoridades e musicalidades tão pertinentes à formação humana.

Não se pode permitir que alunos e alunas sejam impossibilitados, nos espaços educativos de terem acesso a diferentes musicalidades do Mundo, em especial a de cunho africano e afro-brasileiro. Não é mais possivel permitir que a escola seja um espaço de legitimação do racismo epistêmico e da desigualdade racial. É importante que nós, educadores musicais, possamos nos questionar sobre o nosso papel em relação à responsabilidade social e à ética no processo de construção de saberes e conhecimentos partindo da ideia desobediente às hegemônicas maneiras de fazer e praticar Música como bem nos lembra Nilma Lino Gomes ${ }^{13}$ (2013) ao apontar que:

Entender a dimensão do conflito e repensar a prática pedagógica com base no sentido de exercitar uma postura ética poderá nos apontar para liberdade, e não para o aprisionamento do sujeito no preconceito, na desigualdade, na discrimi-

\footnotetext{
13 "Pedagoga/UFMG, mestra em Educação/UFMG, doutora em Antropologia Social/USP e pós-doutora em Sociologia/Universidade de Coimbra. Integra o corpo docente da pós-graduação em educação Conhecimento e Inclusão Social -FAE/UFMG. Foi Coordenadora Geral do Programa de Ensino, Pesquisa e Extensão Ações Afirmativas na UFMG (2002 a 2013) e, atualmente, integra a equipe de pesquisadores desse Programa. Integrou a Câmara de Educação Básica do Conselho Nacional de Educação (gestão 2010 a 2014). Foi reitora Pró-Tempore da Universidade da Integração Internacional da Lusofonia Afro-Brasileira - UNILAB (2013-2014). Foi Ministra da Secretaria de Políticas de Promoção da Igualdade Racial -SEPPIR - (2015) e do Ministério das Mulheres, da Igualdade Racial, da Juventude e dos Direitos Humanos (2015-2016) do governo da presidenta legitimamente eleita, Dilma Rousseff. É membro da Associação Nacional de Pós-graduação e Pesquisa em Educação (ANPED), Associação Brasileira de Antropologia (ABA), Associação Brasileira de Pesquisadores Negros (ABPN).Tem interesse nas seguintes áreas de investigação: diversidade, cultura e educação, relações étnico-raciais e educação, formação de professores e diversidade étnico-racial, políticas educacionais, desigualdades sociais e raciais, movimentos sociais e educação, com ênfase especial na atuação do movimento negro brasileiro". Informações disponiveis em: <http://lattes.cnpq.br/7444449891704854>.
} 
nação e no racismo. A educação para as relações étnico-raciais que cumpre o seu papel é aquela em que as crianças ao passarem pela escola básica, questionem a si mesmas nos seus próprios preconceitos, tornem-se dispostas a mudar posturas e práticas discriminatórias, reconheçam a beleza e a riqueza das diferenças compreendam como essas foram transformadas em desigualdades nas relações de poder e de dominação. Em suma, os sujeitos de uma educação das relações étnico-raciais que se pauta na ética aprenderão a desnaturalizar as desigualdades e, ao fazê-lo, tornar-se-ão sujeitos de sua própria vida e da sua história aprenderão a se posicionar politicamente (e não somente no discurso) contra toda sorte de discriminação. (GOMES, 2013, p. 83)

Assim, proponho uma educação musical, outra. Uma educação musical desobediente, conflitante e descolonizada diante do exercício monocultural, hegemônico e eurocentrado que embasa as concepções, objetivos, metodologias e práticas pedagógicas da contemporaneidade nas escolas de Educação Básica. Um péssimo exemplo é a concepção de currículo vigente: a atual Base Nacional Comum Curricular, em sua $3^{\text {a }}$ versão, sem a inclusão da opinião pública, homologada em 20/12/2017, em Brasília, pelo Ministro da Educação José Mendonça Filho, praticante do governo golpista de Michel Temer. Este documento fundamenta o racismo epistêmico ao retirar da base toda discussão sobre a educação para as relações étnico-raciais, delineadas nas Diretrizes Curriculares Nacionais para Educação das Relações Étnico-Raciais e para o Ensino de História e Cultura Afro-Brasileira e Africana.

Necessitamos mais do que nunca olhar para as produções epistemológicas dos ribeirinhos, das comunidades indígenas, quilombolas e favelas e de tantos outros grupos subalternizados na linha da perversidade do heteropatriarcalismo, colonialismo e capitalismo. Por meio das resistências criativas desses grupos, é importante observar que não dá para ensinar a Música europeia e/ou norte-americanizada somente, como uma única forma de conhecimento. É preciso estarmos atentos á diversidade humana que circula nas escolas, a pluralidade étnica e cultural que esses indivíduos possuem e produzem cotidianamente e a igualdade de direitos que todo/a e qualquer cidadão brasileiro tem: o acesso à educação, como é garantido na Constituição Federal Brasileira de 1988.

E só um adendo: Ao NÃO nos implicarmos e nos responsabilizarmos com a questão racial em nossas ações pedagógico-musicais estaremos nós, educadores musicais, corroborando com a legitimação do racismo e, por si só, sendo responsáveis também pelo aumento de negros e negras assassinados no Brasil, de forma simbólica ou física.

\section{Por uma Pedagogia Musical 3D: decolonial, desobediente e dialógi- ca - perspectivas}

Entender o conceito de coloneidade torna-se importante para pensarmos maneiras decoloniais, desobedientes e dialógicas para o ensinoaprendizagem de Música na Educação Básica. Assim, utilizo a rede de produções epistemológicas desenvolvidas na América Latina, principalmente de autores do Grupo de Pesquisa intitulado “Modernidade/Colonialidade", para nortear a perspectiva de uma Pedagogia Musical 3D. 
O colonialismo é um conceito diferente da ideia de colonialidade, porém, ambos estão interligados. Respectivamente: um fundamentado pelo aspecto escravagista centrado na produção de capital, e o outro articulado com a subalternização e silenciamentos, por meio da perversidade do controle social na/da subjetividade humana - dos corpos negros e de tantas outras etnias massacradas pelo Mundo a fora.

Autores como Maldonato Torres (2007), Walter Mignolo (2003), Ramón Grofouguel (2007), Henrique Dussel (2010) e o próprio Anibal Quijano (2010), defendem que o colonialismo se refere ao padrão de dominação, controle de autoridade político-econômica e militar-imperialista. Esse aspecto desenhado pelos autores latino-americanos revela a densidade da estrutura capitalista existente no mundo sobre povos e nações.

Vale destacar que estudiosos não latino-americanos, do campo de estudos Pós-Coloniais, tais como Homi Bhabha (1998), Stuar Hall (2009), entre outros, entenderam em suas pesquisas que o colonialismo havia se encerrado no Mundo. Sobre uma perspectiva de controle hegemônico, subjetivo e epistemológico, o colonialismo se mantém presente de forma sociocultural, político-econômica e hegemônica, por meio da Modernidade. Para Mignolo (2005) a Modernidade e a colonialidade possuem a mesma face, ou seja, uma é constitutiva da outra.

A colonialidade é um dos elementos constitutivos e específicos do padrão mundial do poder capitalista. Sustenta-se na imposição de uma classificação racial/ étnica da população do mundo como pedra angular do referido padrão de poder e opera em cada um dos planos, meios e dimensões materiais e subjetivos, da existência social cotidiana e de escala social. Origina-se e mundializa-se a partir da América. (QUIJANO ${ }^{14}, 2010$, p. 84)

Quando a Europa fundamenta a ideia de Modernidade como modelo único e universal a existir no Mundo, coloca demarcadores fatais - capitalismo (desigualdade social), patriarcado (discriminação sexual) e o colonialismo (discriminação racial) - como eixos centrais sobre uma sofisticada forma de dominação e opressão sobre países da África, Ásia e América e, assim, seus conhecimentos e saberes são silenciados e deslegitimados.

A colonialidade pode ser entendida com um lócus de dominação do imaginário do outro. Se funda na classificação étnica e racial da população mundial. Utiliza a produção de conhecimento eurocêntrica como centro de construção de saber sobre a repressão de outras formas de conhecimento e saberes existentes no Mundo. Se legitima na subalternização epistemológica do não europeu. Atua na perspectiva geopolítica e cultural de que a Europa é o centro do Mundo.

O processo de colonização no Brasil foi marcado pela destruição do imaginário do outro, esse outro que somos nós, marcados então, por um processo de invisibilização e subalternização, ou seja, um processo de reducionismo da humanidade do outro, o colocando na categoria de primitivos e irracionais, pois pertencem a "outra raça".

\footnotetext{
14 Anibal Quijano é professor emérito da Universidade Mayor de San Marcos, em Lima, Peru. Doutor Honoris causa pela Universidade Central da Venezuela (UCV). Integra o Grupo Modernidade/Colonialidade com outros professores e pesquisadores da América Latina. Possui pesquisa e produção de conhecimento sobre Colonialismo, Colonialidade e Decolonialidade.
} 
Na contemporaneidade, não vivemos mais em uma estrutura do colonialismo, vivemos a herança de forma mais sofisticada, sendo a Europa Ocidental o centro dominante.

Partindo da concepção e da necessidade de erradicação desse pensamento sofisticado de controle social e subjetivo da humanidade, visto do lugar oprimido pela Modernidade e colonialidade, a relação com o campo da Educação está conectada a um projeto de emancipação epistêmica e social. Candau e Oliveira (2010), destacam que

uma questão central num projeto de emancipação epistêmica é a coexistência de diferentes epistemos ou formas de produção de conhecimento entre intelectuais, tanto na academia, quando nos movimentos sociais, colocando em evidência a questão geopolítica do conhecimento. (CANDAU; OLIVEIRA, 2010, p. 23)

Tal perspectiva relaciona-se diretamente com a necessidade de, no campo da Educação Musical, para além de trabalhar com os modelos conservatoriais eurocêntricos monoculturais, termos, no processo de ensinoaprendizagem musical, outras epistemes que são produzidas em outros contextos, lógicas e vivências. Porém, isso requer uma experiência outra, que ultrapassa oo que o pensamento hegemônico nos conduziu sonoramente até agora. É promover, a partir dessas outras epistemologias, a criação de metodologias outras.

Estou chamando a atenção para o reconhecimento dos saberes pluriétnicos que o Brasil, a América Latina, a África, o Mundo possuem. Ou seja, requer a construção de currículos pedagógico-musicais abertos e flexíveis a outras formas e estruturas, nos quais os saberes mantidos como verdade única sejam confrontados e a reinvenção destes cotidianamente construída.

Dada a análise, cabe algumas perguntas para seguimos com a concepção de uma Educação Musical 3D. Quais são as possíveis contribuições do ensinoaprendizagem de Música, sendo ele dialógico, decolonial e desobediente, para a formação humana? De que forma a diversidade musical, e por si só também cultural, tem a favorecer para os (des)silenciamentos?

Partindo do ponto da desobediência e de enfrentamento ao modelo ocidental impregnado em nossas estruturas de saber e conhecimento, ressalto que uma epistemologia ocidental eurocêntrica não permite outro lócus de produção crítica e científica. Pelo contrário: deslegitima saberes outros. Para romper com esse movimento opressor, é necessário o desenvolvimento de projetos educativos emancipatórios e também a coexistência de diferentes epistemes. Desse modo, é imprescindível a demanda por uma virada geopolítica do conhecimento como estratégia contra o pensamento produzido e calcificado pela Modernidade, entendendo que vai além da transformação da descolonização, ou seja, requer "reconstrução radical do ser, do poder e do saber", com nos Walter Mignolo ${ }^{15}$ (2017, p. 24) convida a refletir.

15 Walter Mignolo é argentino e professor de Semiótica da Universidade de Duke. Ele é altamente reconhecido por sua produção acadêmica em torno da questão colonial e geopolítica do conhecimento. Integra o grupo Modernidade/Colonialidade, junto com outros pesquisadores e professores latino-americanos. Para saber mais ver: <http://waltermignolo.com/>. 
O campo da Educação Musical que manuseia suas formas de conhecimento pairadas sobre o saber eurocêntrico impede que brasileiros tenham acesso a produções de saberes - os de tradição, os populares e os culturais - porque estes são entendimentos como menores, por exemplo, na formação de professores. Esse fato não é novo, mas é sempre bom lembrar, sobre o quantitativo de horas de estudo que são destinados, no currículo, aos estudos dos saberes populares e, quando são, no período universitário são mínimas. O texto de Luis Ricardo Silva Queiroz (2017) ${ }^{16}$, intitulado Traços de colonialidade na educação superior em música do Brasil: análises a partir de uma trajetória de epistemicídios musicais e exclusões, nos é pertinente ao debate que estamos realizando neste texto. O autor faz uma análise documental dos cursos de bacharelado em Música e licenciatura em Música, de dez instituições, das cinco regiões do Brasil. As analises desenvolvidas pelo pesquisador apontam a perspectiva colonial, ainda, dada no processo de formação de musicistas e docentes, com um viés da música erudita ocidental, o que legitima a colonialidade institucionalizada na construção de saber.

Os epistemicídios cometidos nos cursos de formação são inúmeros. Dedicamo-nos a formatar as áreas de conhecimentos desses projetos formativos, com cânones que obedecem e legitimam o saber eurocêntrico e abissalmente jogando o outro lado - o invisível, os muitos outros conhecimentos e saberes. Boaventura de Souza Santos ${ }^{17}$, em Epistemologias do Sul (2010), constrói a ideia de epistemicídio, sobre o significado do assassinato, em âmbito de apropriação, do que é do outro, e violência estrutural sobre o outro, ou seja, das epistemes e produções de conhecimento que fogem à estrutura e norma hegemônica.

Nessa esteira, considero pertinente o processo de desobediência. Este por ir contra aos modelos estabelecidos como verdade e único modo de conhecimento entendido pelas ações que envolvem o ensinoaprendizagem musical. É mais do que urgente que tenhamos a coragem de romper com tais estruturas, para a transformação da colonialidade do poder, do saber e do ser, ou seja, conceber visibilidades de outras lógicas e formas de pensar, diferentes da lógica eurocêntrica dominante. É nessa desobediência que, em Educação Musical, pode ser promovida uma pedagogia decolonial. Essa, que vai contra ao modelo estabelecido e tece conflitos para que, dentro de uma criticidade, outras formas criativas de fazer Música possam fazer parte do rol de ensinoaprendizagem. Requer, assim, um "giro epistêmico capaz de produzir novos conhecimentos e outra compreensão simbólica do mundo" (MIGNOLO, 2017, p. 28).

Na composição que muitos enredos estão envolvidos, o processo de Educação Musical, principalmente na escola e na formação dos/das docentes que lá atuam, seja inicial ou continuada, para não ser monocultural e monorracial deve estar atento aos saberes, às crenças, aos conhecimentos e às subjetividades que circulam e constroem o

16 Ver Queiroz (2017), em <http://abemeducacaomusical.com.br/revistas/revistaabem/index.php/revistaabem/issue/current/showToc>.

17 Boaventura de Sousa Santos é Professor Catedrático Jubilado da Faculdade de Economia da Universidade de Coimbra e Distinguished Legal Scholar da Faculdade de Direito da Universidade de Wisconsin-Madison e Global Legal Scholar da Universidade de Warwick. É igualmente Diretor do Centro de Estudos Sociais da Universidade de Coimbra; Coordenador Científico do Observatório Permanente da Justiça. Dirige o projeto ALICE - Espelhos estranhos, lições imprevistas: definindo para a Europa um novo modo de partilhar as experiências o mundo. Possui importantes publicações que tratam das epistemologias do Sul. Para conhecer mais ver: <http://www.boaventuradesousasantos.pt/pages/pt/homepage.php>. 
cotidiano dos espaços de formação, de uma forma ou de outra. Ou seja, bem como nos faz entender Djamila Ribeiro ${ }^{18}$, em $O$ que é lugar de fala?, o olhar nos faz perceber que incluir-se no processo de ampliação do conhecimento requer uma ação participativa, em que, o lócus social dos indivíduos que praticam esses espaços tenham local de existência, e o regime de autoridade imposto pela estrutura hegemônica seja desautorizado.

Portanto, uma pedagogia musical com tessitura decolonial está condicionada a oportunizar o acesso a: a) uma multiplicidade de conhecimentos de músicas e suas formas de fazer, para além do conhecimento que é praticado, a partir do cânone europeu; b) processos criativos que confiram outras formas de escuta de sonoridades que fujam do esquema pitagórico que regimenta a nossas práticas em modelos ocidentalizados; c) vivenciar práticas musicais que envolvam conhecimentos de transmissão oral, tradicional e cultural; d) produções musicais da contemporaneidade configuradas por fenômenos plurais da cultura brasileira e latino-americana, em especial; e) uma educação musical que tenha seu objetivo centrado no humano, entendendo-o e reconhecendo-o com existente e praticante de si no Mundo.

Poderíamos pensar em muitas outras maneiras de fazer justiça cognitiva ${ }^{19}$, mas o intuito desse texto não está centrado em apontar caminhos, mas, sim, pensar perspectivas para uma Educação Musical mais aberta, fluída e construída nos cotidianos em que ela acontece. Para que essa pedagogia esteja compromissada com as demandas gritantes da contemporaneidade, propõe-se repensar os enfoques, as relações de tensão e conflito para uma perspectiva nova de educação musical, ou seja, requer, então, a superação dos padrões epistemológicos hegemônicos para a enunciação epistêmica de saberes e conhecimentos outros. Nesse lugar do comprometimento da Educação Musical com a formação humana, Paulo Freire ${ }^{20}$ (1996) nos provoca a pensar que, nesse processo de uma construção de uma Educação Musical em 3D, é exigido de nós docentes: pesquisa nos cotidianos que desenvolvemos práticas musicais; respeito aos saberes e musicalidades que os educandos praticam nas suas redes de conhecimentos; criticidade ao que é cristalizado enquanto saber instituído com saber (por exemplo a última versão da BNCC, 2017). Exige-se também ética e responsabilidade social com o local em que construímos ensinosaprendizagens, práticas e currículos com estéticas potencialmente imbuídas de diversidade, rejeição a qualquer forma de discriminação - seja ela de gênero, classe ou raça. Requer-se, ainda, da docência: a reflexão crítica sobre a prática cotidianamente; humildade para auto romper com a estrutura hegemônica

\footnotetext{
18 Djamila Ribeito é pesquisadora na área de Filosofia Política e feminista. Foi secretária-adjunta da Secretaria de Direitos Humanos e Cidadania de São Paulo em 2016. Ativista e colunista da revista e site da Carta Capital. Lançou em 2017, pela editora Letramento, a publicação da série Feminismos Plurais - O que é lugar de fala?. Para maiores informações sobre autora sugiro conhecer o site: <https://www.geledes.org.br/tag/ djamila-ribeiro/>.

19 Justiça cognitiva é uma noção que aparece em Santos (2013) e sugere que a pluralidade e o entendimento de que a existência de diferentes conhecimentos, sendo, assim, emancipatória e criando justiça no campo dos saberes. Essa pluralidade parte do reconhecimento da existência de conhecimentos vítimas do epistemicídios cometidos pela Ciência na/da Modernidade. Ou seja, se parte da ideia que só se é possível, no Mundo, fazer justiça social se, antes, a justiça cognitiva for efetivada.

20 Paulo Freire (1921-1997) foi o mais célebre educador brasileiro, com atuação e reconhecimento, no campo da Pedagogia Crítica e Dialógica. Autor de importantes publicações, tais como: Pedagogia da Autonomia e Pedagogia do Oprimido. Para ter mais conhecimento, ver: <http:// www.paulofreire.org/>.
} 
dada na formação docente; convicção de que a mudança epistêmica é possível; generosidade com os múltiplos saberes que não circulam nos espaços educativos e carecem de comprometimento para sua inserção; disponibilidade para o diálogo com o novo.

Por fim, exige-se de nós a compreensão de que a educação é uma forma de intervenção no mundo, como um projeto que tem seu foco na emancipação, perpassada pela prática da escuta aberta ao novo e a criação permeada por outras formas de fazer Música, ou seja, musicalmente falando em três dimensões: desobediente em relação às estruturas perversas aniquiladoras de conhecimentos; decolonial que rompa com as amarras da colonialidade; e dialógica, possibilitando deslocamentos do lugar do outro, para o lugar do nós, este tão importante para a ação da pluralidade humana e a diversidade cultural na Educação Musical.

Para concluir as ideias desse segundo eixo, reforço a necessidade de uma Educação Musical humanizada que reconheça os negrocídios existentes nas práticas educativas e curriculares, por meio do combate à Modernidade cotidianamente, rompendo com a colonialidade e buscando promover ações decoloniais, assumindo, assim, o compromisso epistêmico para a erradicação do racismo institucional e estrutural da sociedade.

\section{O Movimento Negro como prática pedagógica antirracista e musi- cal}

A negritude abre alas, no campo da Música, para enfrentar o racismo. Por meio do convite sonoro-político, regado de enfrentamento desobediente, busca erradicar as audácias negrocídas abissais, por meio das musicalidades postas em composições, canções e letras das mulheres negras e dos homens negros, apresentando-se como um novo paradigma estético, no qual se abre espaço para uma concepção que utiliza esteticamente e poeticamente a Música como arma contra as atrocidades que o povo negro vem sofrendo por décadas com o genocídio físico e simbólico.

Temos visto e presenciado que a inferioridade musical e cultural de diversos gêneros musicais compostos pela negritude sendo jogados nesse outro lado abissal que Santos (2010, p. 34) nos aponta: subentende-se que, do outro lado da linha, "não há conhecimento real; existem crenças, opiniões, magia, idolatria, entendimentos intuitivos ou subjetivos, que, na melhor das hipóteses, podem tornar-se objetivos ou matéria-prima, para a inquirição científica".

Essa linha a qual demarca Boaventura, tem sido avançada e então destituindo o recalque imposto nos meios de fruição e produção e, assim, vemos um movimento negro musical brasileiro forte e potente de combate ao percurso estrutural e institucional do racismo impregnado na esfera social, cultural, econômica e educacional, no Brasil.

Esse movimento eclode uma estética que é do cotidiano, que legitima o lugar de fala, no qual ecoa a grande demanda de todos nós negros e negras: a possibilidade de existir. Existência esta que provoca deslocamentos e embates que perpassados pelo debate sobre gênero, classe e raça.

Ribeiro (2017) nos convida a pensar sobre o lugar que nos inferioriza enquanto negritude, pois, na contemporaneidade, ainda "existe um olhar colonizador sobre nos- 
sos corpos, saberes, produções e, para além de refutar esse olhar é preciso que partamos de outros pontos". Essa é a ação que temos, nós negros, enfrentado por meio das nossas musicalidades estético-políticas, desconcertando os valores-verdades vigentes sobre Música e experiência estética, tecendo aí debates de gênero, classe e raça.

Nessas musicalidades, a ancestralidade de Matriz Africana e Afro-Brasileira fica latente e o nosso lugar de fala vivo e potente, rompendo, então, com os regimes que tendem a nos controlar. Porém, nesse lugar de potência musical criativa, estética e política nos expressamos e identificamos. Nesse lugar de potência, denunciamos o racismo por meio do diálogo interétnico reconhecendo e incorporando a diversidade sonora e cultural, nos processos pedagógico-musicais e artístico-culturais, legitimando e assumindo a nossa ancestralidade como produção simbólica de nós mesmos, ou seja, do lugar em que existimos, o nosso lugar e fala. Com Ribeiro (2017), entende-se esse conceito partindo da ideia que

todas as pessoas possuem lugares de fala, pois estamos falando de localização social. E, a partir disso, é possível debater e refletir criticamente sobre os mais variados temas presentes na sociedade. O fundamental é que indivíduos pertencentes ao grupo social privilegiado em termos de lócus social, consigam enxergar as hierarquias produzidas a partir desse lugar e com esse lugar impacta diretamente na constituição dos lugares de grupos subalternizados (RIBEIRO, 2017, p. 86)

Assim, nada impede que, na escola, tais produções, que representem o lugar de fala da identidade étnica, sejam inseridas no rol de proposições e ações pedagógico-musicais, fazendo com que os praticantes desses espaços, sejam eles negros ou não negros, possam ter acesso a um amplo rol de musicalidades e, assim, possam criar as suas próprias expressões musicais a partir de outras perspectivas, nas quais se agenciem musicalidades que conferem o caráter estético-político de grupos sociais que são entendidos com subalternizados.

Como o subtítulo desse terceiro eixo do artigo bem aponta, a perspectiva estético-sonoro-político que o Movimento Negro tem desenvolvido por meio de musicalidades desobedientes à ordem estética que é inserida nos currículos vigentes para/na Educação Musical, pode ser entendido como uma forma de pedagogia para a diversidade e para a emancipação. Gomes (2017) entende o Movimento Negro como possibilidade e caminhos, nas diversas esferas da sociabilidade, como lugar de existência, e ressalta que é uma das

mais diversas formas de organização e articulação de negras e dos negros politicamente posicionados na luta contra o racismo e que visam à superação desses perversos fenômeno na sociedade. Participam dessa definição os grupos políticos, acadêmicos, culturais, religiosos e artísticos com o objetivo explícito de superação do racismo e da discriminação racial, de valorização e afirmação da história e da cultura dos negros nos Brasil, de rompimento das barreiras racistas impostas aos negros e às negras na ocupação dos diferentes espaços e lugares na sociedade. Trata-se de um movimento que não se reposta de forma romântica à relação entre negros brasileiros e à ancestralidade africana e ao continente 
africano da atualidade, mas reconhece os vínculos históricos, políticos e culturais dessa relação, compreendendo-a como integrante da complexa diáspora africana (GOMES, 2017, p. 23-24).

Pensando em Educação para as relações étnico-raciais e, especificamente em Educação Musical, essa abordagem que o Movimento Negro propõe é uma ação que perpassa questões plurais nas quais o fazer musical pode ser um arcabouço de possibilidades e encontros com outras sonoridades e musicalidades que não fazem parte do rol pedagógico elencado nas práticas educativas. Tomar consciência e buscar inserções diversificadas com a diversidade musical negra e não negra, diga-se de passagem, pode ser uma ação ética, com real compromisso social, com a qual a docência tem com a formação humana.

Ao elaborarmos essa questão como prática pedagógica interétnica, diretamente ou indiretamente, temos visto nas musicalidades negras atravessamentos que alicerçam o debate contra a intolerância religiosa negra, a favor da luta contra o feminicídio e contra a discriminação racial, com uma roupagem sofisticada e conectada com as questões que a contemporaneidade nos apresenta.

Diversos trabalhos denunciam as questões relacionadas ao feminicídio que, com a garra da mulher negra, desestrutura as bases do colonialismo ainda demarcado sobre nossos corpos negros, ou seja, na "carne mais barata do mercado". Mulheres, de um ponto interseccional rompem com o silêncio imposto pelo patriarcalismo e colonialismo, pautando suas obras sobre o debate de gênero, classe e raça.

Outros debatem sobre a inserção dos corpos negros, nos espaços educativos e ecoam em ampla tessitura que "cota não é esmola". Ou seja, aborda-se a questão tão debatida sobre as cotas raciais, que hoje são cotas sociais - para indivíduos pertencentes à escola pública de Educação Básica. Projeto encabeçado pelo Movimento Negro como promulgação das ações afirmativas.

Essas musicalidades desenvolvidas e praticadas por negras e negros ${ }^{21}$ abrem espaço e trazem para uma concepção que utiliza a poética negra como arquétipo resistente e resiliente. São, sem dúvida, uma forma de existência e enfrentamento contra a opressão de caráter racial, na luta pela sobrevivência. Nesse campo de potência de gêneros musicais e repertórios sonoros da negritude tais com: hip-hop, rap, funk carioca, 150bpm, R\&B, trap, twerk, afrohouse, bahia bass, dancehall, afrobeat, kuduro e as mais variadas acústicas desse escopo batidão, são a face da negritude. Acredito que o enaltecimento da música do gueto é potente e catalizador de empoderamento, libertação e emancipação.

A estética da musicalidade negra pode ser amplamente trabalhada a partir de um trabalho acústico, conforme é proposto por Samuel Araújo $(1992,1999)$. O conceito cunhado pelo autor gera, indiscutivelmente, o deslocamento do que se entende por Música. Assim, busca-se relacionar a sonoridade com o espaço e o tempo, enquanto

21 Elza Soares, Karol Conka, Luedji Luna, Mc Carol, Iza, Emicida, Rincon Sapiência, Fabriccio, Tássia Reis, Rico Dalasam, Xênia França, Nara Couto, Mc Soffia, Serena Assumpção, Raquel Virginia, Caio Prado, Liniker, Anelis Assumpção, Ellen Oléria, Juçara Marçal, Bia Ferreira - são alguns potentes nomes da cena da musicalidade negra do enfrentamento e tombamento estético, político e sonoro. 
aspecto de produção e o lócus social de quem a faz, como superação de questões cristalizadas no campo da Música, para além da visão evolucionista, conforme o autor aponta em seus estudos.

Pensar uma Educação Musical descolonizada, desobediente e dialógica perpassa o real compromisso com a inserção de práticas educativas emancipatórias que incorporam no currículo os saberes e conhecimentos plurais vistos a partir de seus próprios ângulos. Ou seja, uma Educação Musical comprometida com bases epistemológicas e metodológicas alicerçadas por saberes outros, que, de alguma forma, não são legitimados como conhecimentos, buscando romper com os epistemicídios praticados.

$E$, nessa proposição pedagógica, que tem seu cerne no diálogo entre Educação Musical e Educação para as relações étnico-raciais, é essencial o reconhecimento da diversidade cultural que cotidianamente circula na escola, como potência criativa e essencial para o combate ao racismo - face mais perversa da sociedade brasileira.

\section{Considerações Finais}

As provocações postas nesse artigo, acerca das Diretrizes Curriculares Nacionais para Educação das Relações Étnico-Raciais e para o ensino da História e Cultura Afro-Brasileira e Africana são um convite para repensarmos o campo da Educação Musical de forma descolonizada, dialógica e desobediente, para além das hegemônicas ações produzidas pelo pensamento eurocêntrico e norte-americanizado, epistemicida nos cotidianos escolares, nas pesquisas acadêmicas e nas práticas musicais quando são estereotipadas pelo pensamento branco, burguês e racial.

É mais do que emergente e urgente a produção de contínuo e sistemático diálogo entre escola e realidade social, para a construção de um currículo de ensinoaprendizagem de Música como um projeto educativo emancipatório, no qual o processo de Educação Musical, a partir do exercício da docência, esteja comprometido eticamente com a formação humana de/com tantos indivíduos que circulam nos espaços educativos.

A Lei 10.639/2003 que perpassa distintas as áreas do conhecimento, a meu ver, gera grande importância de diálogo com a Lei 11.769/200822 que trata do ensinoaprendizagem musical no currículo da Educação Básica, como meio para articular reparações políticas, culturais e sociais no que se refere à visibilidade, representatividade e reconhecimento da negritude. Ou seja, reconhecimento este que implica promover justiça social mediada pela justiça cognitiva, entendimento da igualdade de direitos e respeito à diferença. Implica repensar práticas pedagógicas musicais com epistemologias diversificadas e conhecimentos culturais outros.

Fortalece-me a ideia de que é sim um dos compromissos sociais da escola tratar da questão racial por ser uma perspectiva que não é somente dos negros e negras e, sim, de todos e todas que vivem a colonialidade, na contemporaneidade, dada pela manutenção da discriminação racial, invisibilidade cultural e desigualdade social, ge- 
radas pelo patriarcalismo, capitalismo e colonialismo. Concluo as minhas provocações ressaltando mais uma vez o que Gomes (2012) nos alerta ao apontar que é necessário descolonizar os currículos e as práticas educativas, pois

muito já denunciamos sobre a rigidez das grades curriculares, o empobrecimento do caráter conteúdista dos currículos, a necessidade de diálogo entre escola, currículo e realidade social, a necessidade de formar professores e professoras reflexivos e sobre as culturas negadas e silenciadas nos currículos. (GOMES, 2012, p. 102)

$E$, assim, pensar que se trata de um compromisso de todos e todas nós. E, em especial no campo da Educação Musical, pensarmos sempre em uma relação interétnica em nossas proposições de ensinoaprendizagem, em nossos currículos e práticas pedagógicas musicais, reconhecendo as identidades culturais sem "daltonismos" e, então, evidenciar a história cultural dos negros e das negras como produção de conhecimento tão viva na diversidade cultural brasileira.

\section{Referências}

ADICHIE, Chimamanda Ngozi. O perigo de uma única história. 2009. Disponível em: <https://www.youtube.com/watch?v=wQk17RPuhW8>. Acesso em: 18 fev. 2018.

ALVES, Nilda. Decifrando o pergaminho - os cotidianos das escolas nas lógicas das redes cotidianas. In: OLIVEIRA, Inês Barbosa; ALVES, Nilda (Org.). Pesquisas nos/dos/ com os cotidianos das escolas: sobre redes de saberes. Petrópolis: DP et Alii, 2008.

ARAÚJO, Samuel. Acoustic labor in the timing of everyday life. A critical contribution to the history of samba in Rio de Janeiro. Tese de doutorado em Musicologia. Urbana, IL: University of Illinois em Urbana-Champaign, 1992. Disponível em: <https://www. ideals.illinois.edu/handle/2142/72434>. Acesso em: 9 out. 2018.

Brega, samba e trabalho acústico: variações em torno de uma contribuição teórica à etnomusicologia. Revista Opus, v. 6, Belo Horizonte: ANPPOM, 1999. Disponível em: <https://www.anppom.com.br/revista/index.php/opus/article/ view/69>. Acesso em: 9 out. 2018.

BHABHA, Homi K. O local da cultura. Belo Horizonte: Editora da UFMG, 1998.

BRASIL. Lei no 9.394, de 20 de dezembro de 1996. Estabelece as diretrizes e bases da educação nacional. República Federativa do Brasil, Brasília, 1996. Disponível em: <http://www6.senado.gov.br/ legislacao/ListaPublicacoes.action?id=102480>. Acesso em: 12 fev. 2018. 
BRASIL. Lei no 10.639, de 09 de janeiro de 2003. Altera a Lei no 9.394, de 20 de dezembro de 1996, que estabelece as diretrizes e bases da educação nacional, para incluir no currículo oficial da Rede de Ensino a obrigatoriedade da temática "História e Cultura Afro-Brasileira", e dá outras providências. República Federativa do Brasil, Brasília, 2003. Disponível em: <http://www.planalto.gov.br/ccivil_03/leis/2003/ 110.639.htm>. Acesso em: 12 fev. 2018.

BRASIL. Ministério da Educação. Conselho Nacional de Educação. Conselho Pleno. Resolução n. 1, de 17 de junho de 2004. Institui Diretrizes Curriculares Nacionais para a Educação das Relações Étnico-Raciais e para o Ensino de História e Cultura AfroBrasileira e Africana. República Federativa do Brasil, Brasília, 2004. Disponível em: <http://portal.mec.gov. br/cne/arquivos/pdf/res012004.pdf>. Acesso em: 4 fev. 2018.

BRASIL. Lei no 11.645, de 10 de março de 2008. Altera a Lei no 9.394, de 20 de dezembro de 1996, que estabelece as diretrizes e bases da educação nacional, para incluir no currículo oficial da Rede de Ensino a obrigatoriedade da temática "História e Cultura Afro-Brasileira", e dá outras providências. República Federativa do Brasil, Brasília, 2008b. Disponível em: <http://www.planalto.gov.br/ccivil_03/_ato20072010/2008/lei/l11645.htm>. Acesso em: 24 mar. 2018.

BRASIL. Lei no 11.769, de 18 de agosto de 2008. Altera a Lei no 9.394, de 20 de dezembro de 1996, Lei de Diretrizes e Bases da Educação, para dispor sobre a obrigatoriedade do ensino da música na educação básica. República Federativa do Brasil, Brasília, 2008c. Disponível em: <http://www.planalto.gov.br/ccivil_03/_ Ato20072010/2008/Lei/L11769.htm>. Acesso em: 12 fev. 2018.

BRASIL. Resolução CNE/CEB no 2, de 10 de maio de 2016. Define Diretrizes Nacionais para a operacionalização do ensino de Música na Educação Básica. Brasília, DF, 2016b. Disponível em: <mec.gov.br/index.php?ption=com_ docman\&view=download\&alias=40721-rceb002-16-pdf\&category_slug=maio-2016pdffltemid=30192>. Acesso em: 12 jan. 2018.

BRASIL, Anistia Internacional. 2014. Campanha Jovem Negro Vivo. Disponível em: <https://anistia.org.br/campanhas/jovemnegrovivo/>. Acesso em: 12 janeiro de 2018.

CANDAU, Vera Maria Ferrão; OLIVEIRA, Luiz Fernandes de. Pedagogia decolonial e educação antirracista e intercultural no Brasil. Educação em Revista, Belo Horizonte, v. 26, n. 1, p. 15-40, 2010. Disponível em <http://www.scielo.br/scielo.php?pid=S010246982010000100002 \&script=sci_abstract\&tlng=pt>. Acesso em: $18 \mathrm{de} \mathrm{fev.} 2018$. 
CAMPBELL, Patricia Shehan. Etnomusicología y educación musical: punto de encuentro entre música, educación y cultura. RIEM: Revista Internacional de Educação Musical, n. 1, p. 42-52, 2013. Disponível em: <http://www.revistaeducacionmusical. org/index.php/rem1/article/view/29>. Acesso em: 9 out. 2018.

CARVALHO, José Jorge de. Los estudios culturales en América Latina: interculturalidad, acciones afirmativas y Encuentro de Saberes. Tabula Rasa, Bogotá, n. 12, p. 229-251, 2010. Disponível em: <http://www.scielo.org.co/pdf/tara/n12/n12a14.pdf>. Acesso em: 9 out. 2018.

CARVALHO, José Jorge de; ÁGUAS, Carla. Encontro de Saberes: um desafio teórico, político e epistêmológico. In: SANTOS, Boaventura de Sousa; CUNHA, Teresa (Org.). Actas do Colóquio Internacional Epistemologias do Sul: aprendizagens globais sulsul, sul-norte e norte-sul. Democratizar a Democracia. Coimbra: Universidade de Coimbra, 2015. v. 1. Disponível em: <http://alice.ces.uc.pt/coloquio_alice/wp-content/ uploads/2015/08/Livro_DD.pdf>. Acesso em: 9 out. 2018.

CERTEAU, Michel. A invenção do cotidiano, 1. Artes de fazer. Petrópolis: Vozes, 1994.

FANON, Frantz. Pele negra, máscaras brancas. Bahia: Editora Edufba, 2008.

FREIRE, Paulo. Pedagogia da autonomia. São Paulo: Editora Paz e Terra, 1996.

GOMES, Nilma Lino. O Movimento Negro educador: saberes construídos nas lutas por emancipação. Petrópolis, RJ: Vozes, 2017.

Relações étnico-raciais, educação, descolonização dos currículos. Currículo sem Fronteiras. v. 12, n. 1, jan/abr, 2012. p. 90-109. Disponível em: <http://www. curriculosemfronteiras.org/vol12iss1articles/gomes.pdf>. Acesso em: 9 out. 2018.

A questão racial na escola: desafios colocados pela implementação da Lei 10.629/03. In: Multiculturalismo: diferenças culturais e práticas pedagógicas. (Org.) Antônio Flávio Moreira, Vera Marai Candau. 10. Ed. - Petrópolis, RJ: Vozes 2013.

GROSFOGUEL, Ramón. Descolonizando los universalismos occidentales: el pluriversalismo transmoderno decolonial desde Aimé Césaire hasta los zapatistas. In: CASTRO-GÓMEZ, Santiago \& GROSFOGUEL, Ramon (coords.) El giro decolonial: reflexiones para uma diversidad epistêmica más allá del capitalismo global. Bogotá: Siglo del Hombre Editores, Universidad Central, Instituto de Estudios Sociales Contemporáneos, Pontificia Universidad Javeriana, Instituto Pensar. 2007

HALL, Stuart. Identidades culturais na pós-modernidade. Trad. Tomaz Tadeu da Silva; Guacira Lopes Louro. Rio de Janeiro: DP\&A, 2006. 
IPEA. Instituto de Pesquisa Econômica Aplicada. 2017. Atlas da Violência. Disponível em: <http://www.ipea.gov.br/atlasviolencia/download/2/atlas-2017>. Acesso em 12 jan. 2018.

LUCAS, Glaura; QUEIROZ, Luis Ricardo Silva; PRASS, Luciana; RIBEIRO, Fábio Henrique; AREDES, Rubens de Oliveira. Culturas Musicais Afro-Brasileiras: perspectivas para concepções e práticas etnoeducativas em Música. In: Etnomusicologia no Brasil, (Org.) de Angela Luhning e Rosângela Pereira de Tugny. Salvador, BA: Editora UFBA, 2017.

LÜHNING, Ângela. Temas emergentes da etnomusicologia brasileira e seus compromissos sociais. In: Música em perspectiva, v. 7, nำ02, pp. 07-25. Curitiba: UFPR, 2014. <https://revistas.ufpr.br/musica/article/view/41501>. Acesso em: 9 out. 2018.

MALDONADO-TORRES, Nelson. Pensamiento crítico desde la sub-alteridad: los estudios étnicos como ciencias descoloniales o hacia la transformación de las humanidades y las ciencias sociales en el siglo veintiuno. In: Saavedra, José Luis (Ed.). Educación superior, interculturalidad y descolonización, p. 145-174. La Paz: Programa de Investigación Estratégica en Bolivia; Comité Ejecutivo de la Universidad Boliviana, 2007. Disponível em: <http://www.redalyc.org/pdf/4575/457545365008.pdf>. Acesso em: 9 out. 2018.

MIGNOLO, Walter. Desafios decoloniais hoje. In: Revista Epistemologias do Sul. Foz do Iguaçu - PR, (1), p.12-32, 2017.

Histórias locais/projetos globais: colonialidade, saberes subalternos e pensamento liminar. Tradução de Solange Ribeiro de Oliveira. Belo Horizonte, Ed. UFMG, 2003.

QUEIROZ, Luis Ricardo Silva; MARINHO, Vanildo Mousinho. Educação musical e etnomusicologia: lentes interpretativas para a compreensão da formação musical na cultura popular. Opus, v. 23, n. 2, p. 62-88, 2017. <https://www.anppom.com.br/ revista/index.php/opus/article/view/477>. Acesso em: 9 out. 2018.

QUEIROZ, Luis Ricardo Silva. Traços de colonialidade na educação superior em música do Brasil: análises a partir de uma trajetória de epistemicídios musicais e exclusões. In: REVISTA DA ABEM, Londrina, v.25, n.39, 132-159, jul.dez. 2017. Disponível em: (http:// www.abemeducacaomusical.com.br/revistas/revistaabem/index.php/revistaabem/ article/view/726/501). Acesso em: 9 out. 2018.

QUIJANO, Anibal. Colonialidade do poder e classificação social. In: SANTOS, Boaventura de Sousa; MENESES, Maria Paula. (Orgs.). Epistemologias do Sul. São Paulo: Cortez, 2010. 
RIBEIRO, Djamila. O que é lugar de fala?. São Paulo: Grupo Editorial Letramento, 2017.

SANTOS, Boaventura Souza. Toward a New Comoon Sense: law, Science and politics in the oaradigmatic transisition. Nova lorque: Routledge, 1995.

Para além do pensamento abissal: das linhas globais a uma ecologia dos saberes In: SANTOS, Boaventura de Sousa; MENESES, Maria Paula. (Orgs.). Epistemologias do Sul. São Paulo: Cortez, 2010. 